\title{
Localization of a Pathogenicity Gene in Ophiostoma novo-ulmi and Evidence That It May Be Introgressed from O. ulmi
}

\author{
Abdelali Et-Touil, ${ }^{1}$ Clive M. Brasier, ${ }^{2}$ and Louis Bernier ${ }^{1}$ \\ ${ }^{1}$ Centre de recherche en biologie forestière (CRBF), Pavillon C.-E. Marchand, Université Laval, Sainte-Foy, \\ QC, Canada G1K 7P4; ' $F$ Forest Research Station, Alice Holt Lodge, Surrey, UK GU10 4LH \\ Accepted 29 September 1998.
}

\begin{abstract}
Ophiostoma novo-ulmi, the principal agent of Dutch elm disease, has recently replaced another species of Dutch elm disease pathogen, $O$. ulmi, across much of the Northern Hemisphere. Field inoculations of the moderately resistant elms Ulmus procera and Ulmus $\times$ Commelin were carried out with progeny of a genetic cross between AST27, a Eurasian (EAN) O. novo-ulmi isolate with an unusually low level of pathogenicity, and H327, a highly aggressive EAN isolate. These confirmed the results of a previous study that indicated that the difference in phenotype was controlled by a single nuclear gene. This pathogenicity gene, designated here Pat1, is the first putative pathogenicity gene to be identified in $O$. novo-ulmi. In a bulked segregant analysis, involving 80 random primers, 10 RAPD (random amplified polymorphic DNA) markers were identified linked to Pat1. Linkage distances between these markers and Pat 1 were confirmed by genetic analysis of all individual progeny. Five RAPD amplicons identified in AST27 were $O$. ulmi and not $O$. novo-ulmi specific amplicons, and of these two were linked to Pat1. This suggests that the Pat1 allele conferring unusually low aggressiveness in AST27 may have been acquired from $O$. ulmi via introgression. When RAPD marker OPK $3_{1050}$, linked to Pat1, was used as a probe for Southern hybridization with electrophoretically separated chromosomes of $O$. novo-ulmi and $O$. ulmi, the results indicated that Pat1 is located on a $3.5 \mathrm{Mb}$ chromosome previously designated chDNA II.
\end{abstract}

Since the 1920s, Dutch elm disease has destroyed most stands of mature native elms (Ulmus spp.) in Canada, the United States, and Europe. Across these regions, the disease is caused by two species of fungal pathogen in the genus Ophiostoma: the less aggressive O. ulmi (Buisman) Nannfeldt and the highly aggressive $O$. novo-ulmi Brasier. The latter is further subdivided into the Eurasian (EAN) and North American (NAN) races, which are considered equivalent to subspecies (Brasier 1991). O. ulmi is associated with the first pandemic of the disease, which began in northwest Europe in the early 1900s. O. novo-ulmi is associated with the current, much more destructive second pandemic of the disease, and has now

Corresponding author: L. Bernier; E-mail: lbernier@rsvs.ulaval.ca replaced $O$. ulmi throughout most of North America, Europe, and southwest and central Asia (Brasier 1990). In nature, there is strong but not total reproductive isolation between $O$. ulmi and O. novo-ulmi (Brasier 1977; Kile and Brasier 1990) and partial reproductive isolation between the EAN and NAN races of O. novo-ulmi (Brasier 1979). A third highly aggressive Dutch elm disease pathogen, O. himal-ulmi Brasier and Mehrotra, is endemic to and has so only been recorded in the Himalayas (Brasier and Mehrotra 1995).

The genetic and physiological basis of pathogenicity in the Dutch elm disease pathogens remains little understood. A large and discontinuous difference in aggressiveness between $O$. ulmi and O. novo-ulmi on elms of moderate resistance is accompanied by many other phenotypic differences between them (Brasier 1991) including a marked difference in production of the phytotoxic protein cerato-ulmin (Takai 1980; Brasier et al. 1990). However, in crosses between $O$. ulmi and $O$. novo-ulmi the ascospores are of low viability and the associations are not conserved in the progeny (Brasier 1977, 1987; Bernier 1983; Kile and Brasier 1990), indicating that they mainly reflect adaptive differences accumulated since the evolutionary divergence of the two species. Cerato-ulmin is now believed to have a more limited role in pathogenicity than previously supposed (Brasier et al. 1995; Bowden et al. 1996; Temple et al. 1997), while the role of various other metabolites implicated in the pathogenicity of $O$. ulmi and O. novoulmi remains unclear (Scheffer et al. 1987).

Crosses within $O$. novo-ulmi may offer a better opportunity for elucidating the genetic basis of pathogenesis. A study of intra-specific variation in $O$. novo-ulmi revealed a greater range of variation in pathogenicity within the EAN race than within the NAN (Brasier 1986). One EAN isolate in particular, AST27, fell well below the normal pathogenicity range for EAN isolates, lying as a distinct intermediate between the other EAN O. novo-ulmi isolates and the weakly pathogenic O. ulmi control isolates. To investigate underlying genetic controls, crosses were carried out between EAN isolates of differing levels of aggressiveness. Crosses between isolates of higher levels of aggressiveness suggested only small, mainly additive heritable effects. However, in the cross AST27 (lower aggressiveness) $\times$ H327 (high aggressiveness) and another similar cross, a total of 28 progeny segregated in a near $1: 1$ ratio. This indicated that a single major gene was responsible for the unusually low aggressiveness of AST27 (Brasier 
1987). The main objectives of the present study were to confirm the existence of this gene in O. novo-ulmi and to determine its location in the nuclear genome as a prelude to investigating its DNA sequence. Another objective was to investigate whether the gene might be introgressed from $O$. ulmi (cf. Brasier et al. 1998). Isolates AST27 and H327 were crossed again and a larger set of progeny were recovered, inoculated into clonal elms, and genetically characterized by random amplified polymorphic DNA-polymerase chain reaction (RAPD-PCR). Bulked segregant analysis (BSA) was used to identify RAPD markers linked to the putative pathogenicity gene. One of these RAPD markers was hybridized with chromosomes separated by pulsed-field gel electrophoresis (PFGE).

\section{RESULTS}

\section{Pathogenicity tests.}

Forty single-ascospore progeny were initially recovered from the cross $\mathrm{H} 327 \times$ AST27. The first field inoculation test of these $\mathrm{F}_{1} \mathrm{~s}$ on Ulmus $\times$ Commelin in June 1995 resulted in unusually low levels of defoliation, due to environmental conditions (see Sutherland et al. 1997). The highly aggressive parent, H327, induced only $13.2 \%$ mean defoliation (range 10 to $18 \%$ ), while the values for 21 presumptively more aggressive progeny ranged from 9 to $18 \%$ (Fig. 1A). The moderately aggressive parent, AST27, induced 5.6\% mean defoliation, while 19 presumptively less aggressive progeny ranged from 1 to $7 \%$ (Fig. 1A). The two groups of progeny, however, did not differ significantly $(P=0.05)$. When some of the trees were destructively sampled at the end of the experiment, all showed extensive vascular browning throughout the crown. The mean proportion of stem length affected by internal streaking for all 10 replicates of $\mathrm{H} 327$ was $100 \%$ and for those of AST27, $75.4 \%$. The mean value for eight more aggressive progeny isolates examined was $99.3 \%$ (range 83 to $100 \%$ ) and for eight less aggressive progeny $76.9 \%$ (range 54 to $100 \%$ ).

Field inoculation of clonal $U$. procera with the same $F_{1}$ isolates in June 1996 resulted in more typical external symptom development. It also confirmed the above progeny groupings (Fig. 1B). Isolate H327 induced a mean of $62.3 \%$ crown defoliation, and AST27 17.5\%. Two groups, differing significantly in pathogenicity $(F=14.53, P<0.0001)$, occurred in the progeny. A more aggressive group, comprising the same 21 isolates as above, caused 43 to $61 \%$ defoliation (mean 54.5\%). A less aggressive group of 19 isolates caused only 10 to $29 \%$ defoliation (mean $19.4 \%$ ). The two groups conformed to a $1: 1$ segregation $\left(X^{2}=0.1<\right.$ critical value $=$ 3.84, $P=0.05)$.

This result was therefore consistent with occurrence of alleles for high and moderate pathogenicity at a single locus (Brasier 1987). We have termed this putative pathogenicity locus Pat1. This conclusion was further tested by analyzing 50 progeny from a backcross between the moderately aggressive $\mathrm{F}_{1}$ progeny isolate $\mathrm{A} 2 \mathrm{P} 30$ and $\mathrm{H} 327$. Field inoculations of clonal $U$. procera were carried out in June 1997. Once again, significant differences in pathogenicity $(F=12.22, P<$ 0.0001 ) were observed between the parents and among the progeny (Fig. 2). The mean defoliation induced by isolates in a less aggressive group $(n=22)$ ranged from 17 to $27 \%$, whereas that induced by a more aggressive group $(n=26)$ ranged from 42 to $60 \%$. The two groups again segregated $1: 1$ $\left(X^{2}=0.33<\right.$ critical value $\left.=3.84, P=0.05\right)$. Two isolates, A3P7 and A3P40, could not be readily assigned to either group, since they caused intermediate levels of defoliation (Fig. 2).

\section{Identification and analysis of RAPD markers linked to Pat1.}

Total genomic DNA from 12 highly aggressive (A2P2, A2P4, A2P5, A2P8, A2P9, A2P18, A2P21, A2P22, A2P25, $\mathrm{A} 2 \mathrm{P} 32, \mathrm{~A} 2 \mathrm{P} 34, \mathrm{~A} 2 \mathrm{P} 37)$ and 12 moderately aggressive (A2P6, $\mathrm{A} 2 \mathrm{P} 10, \mathrm{~A} 2 \mathrm{P} 12, \mathrm{~A} 2 \mathrm{P} 15, \mathrm{~A} 2 \mathrm{P} 17, \mathrm{~A} 2 \mathrm{P} 24, \mathrm{~A} 2 \mathrm{P} 26, \mathrm{~A} 2 \mathrm{P} 27$, $\mathrm{A} 2 \mathrm{P} 28, \mathrm{~A} 2 \mathrm{P} 30, \mathrm{~A} 2 \mathrm{P} 36, \mathrm{~A} 2 \mathrm{P} 40) \mathrm{F}_{1}$ isolates was pooled into two bulks. Parent DNA and bulked DNA were screened with 80 RAPD primers. Approximately $90 \%$ of the latter produced reproducible amplification patterns in both parents and bulks. Screening revealed that 20 primers gave polymorphic DNA fragments between the parents. Ten of these primers generated polymorphisms that were also observed between the bulks: OPA $18_{620}, \quad \mathrm{OPC}_{16} 6_{1890}, \mathrm{OPC}_{16} 6_{2610}, \mathrm{OPC} 18_{940}, \mathrm{OPC} 19_{920}$, OPJ $18_{410}, \mathrm{OPJ} 18_{2750}, \mathrm{OPJ} 20_{540}, \mathrm{OPK} 3_{1050}$, and OPK $10_{1270}$ (Fig. 3). In order to confirm genetic linkage between Pat1 and RAPD loci identified by BSA, DNA from all individual $F_{1}$ progeny strains was amplified with the 10 RAPD primers. Recombination analysis showed that three RAPD markers $\left(\mathrm{OPC} 16_{2610}\right.$, OPJ $20_{540}$, and OPK $\left.3_{1050}\right)$ cosegregated with the Patl allele conferring high pathogenicity (Pat $1-h)$, suggesting that they were located less than 2.5 map units from Pat1 (Fig. 4A). Markers OPA18 $8_{620}$, OPC16 $6_{1890}$, OPC18 $8_{940}$, OPC19 1920 , OPJ18 ${ }_{410}$, OPJ18 2750 , and OPK10 1270 were also linked to Pat1, although less tightly, as shown by the recovery of recombinants. Markers OPC $16_{1890}$ and OPJ18 ${ }_{2750}$ were present in the moderately aggressive parent (AST27) and in most isolates of the less aggressive progeny group, suggesting that these markers are associated with the allele conferring lower pathogenicity $($ Pat $1-m)$. Recombination analysis of 50 backcross progeny (Figs. 4B and 5) confirmed linkage between Pat1 and seven of the 10 RAPD markers identified by BSA. The remaining three markers (OPC18 $8_{940}$, OPK10 1270 , and OPA18 620 ) could not be scored in the backcross progeny since parents H327 and A2P30 carried similar alleles at these loci. Markers $\mathrm{OPC}_{16} 6_{2610}, \mathrm{OPJ} 20_{540}$, and OPK $3_{1050}$, which cosegregated with Patl in the $\mathrm{F}_{1}$ progeny, recombined with Patl $(\% R=8.0)$ in the backcross progeny. The recombination frequency between Pat1 and OPC19 $9_{920}$ was much lower in the backcross $(\% R=$ $2.0)$ than in the $\mathrm{F}_{1}(\% R=34.1)$. However, the relative order of markers was very similar in both maps (Fig. $4 \mathrm{~A}$ and B).

\section{Chromosome electrophoresis.}

The chromosomes of $O$. novo-ulmi and $O$. ulmi were separated under PFGE conditions described by Dewar and Bernier (1993). Generally, five to seven chromosomes ranging in size from 1.0 to $>5.7 \mathrm{Mb}$ were visible (Fig. 6A). Electrophoretic karyotypes observed for NAN O. novo-ulmi strains $16 \mathrm{~K}$ and FG245 were similar to those previously reported (Dewar and Bernier 1995). Clamped homogeneous electric field (CHEF) analysis of chDNA from NAN $O$. novo-ulmi strain W2 confirmed a previous report, based on a different technique (Dewar and Bernier 1993), that this strain has a karyotype similar to that of FG245. O. ulmi isolate Q412T had six visible chDNA bands, ranging from $2.7 \mathrm{Mb}$ (band VI) to $>5.7 \mathrm{Mb}$ 
(band I). Two chDNA bands (II and III) were similar in size to bands found in O. novo-ulmi reference strain 16K. Five chDNA bands ranging from 2.7 to $>5.7 \mathrm{Mb}$ were visible in parental strains $\mathrm{H} 327$ and AST27 and in $\mathrm{F}_{1}$ progeny strains A2P2 (Pat-h) and A2P6 (Pat-m). Bands I to IV appeared to be monomorphic and similar in size to bands found in isolate
$16 \mathrm{~K}$. Band $\mathrm{V}$, however, appeared to be polymorphic since its mobility was slightly higher in strains AST27 and A2P2. A small $(1 \mathrm{Mb})$ chDNA characteristic of strain 16K (Dewar and Bernier 1993, 1995; Dewar et al. 1997) was not observed in any of the other isolates analyzed in this study. Results from a Southern hybridization of the PFGE-separated chromosomes
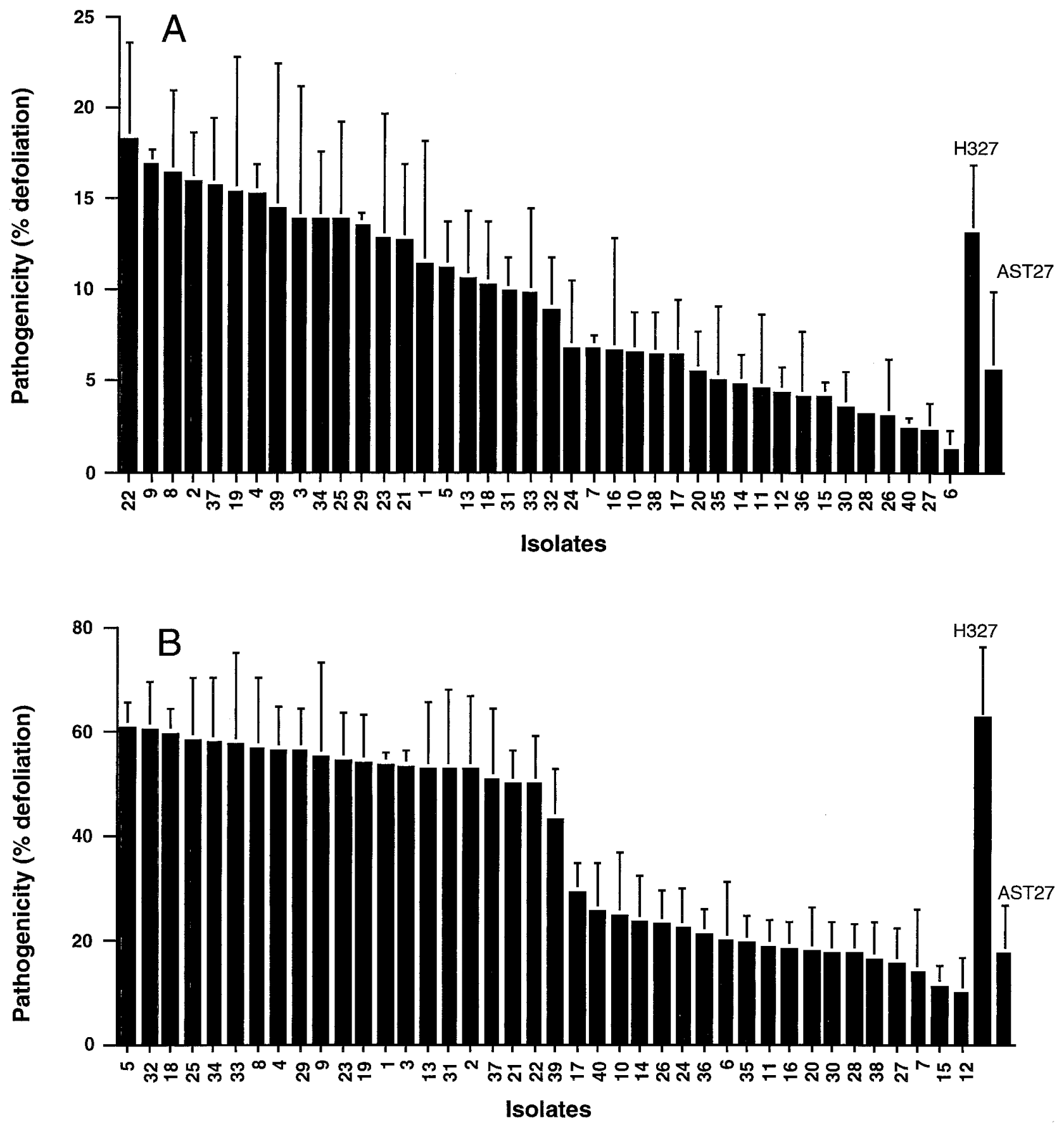

Fig. 1. Pathogenicity distribution for $40 \mathrm{~F}_{1}$ single-ascospore progeny from a cross between a moderately (AST27) and a highly (H327) aggressive isolate of Eurasian (EAN) Ophiostoma novo-ulmi. A, Inoculations were carried out on Ulmus $\times$ Commelin in June 1995. Progeny strains were inoculated into three replicate trees, whereas parents were inoculated into 10 replicate trees. B, Inoculations were carried out on U. procera in June 1996. Progeny strains were inoculated into four replicate trees, whereas parents were inoculated into eight replicate trees. Vertical bars indicate standard error. Crown defoliation was assessed 12 weeks after inoculation. 


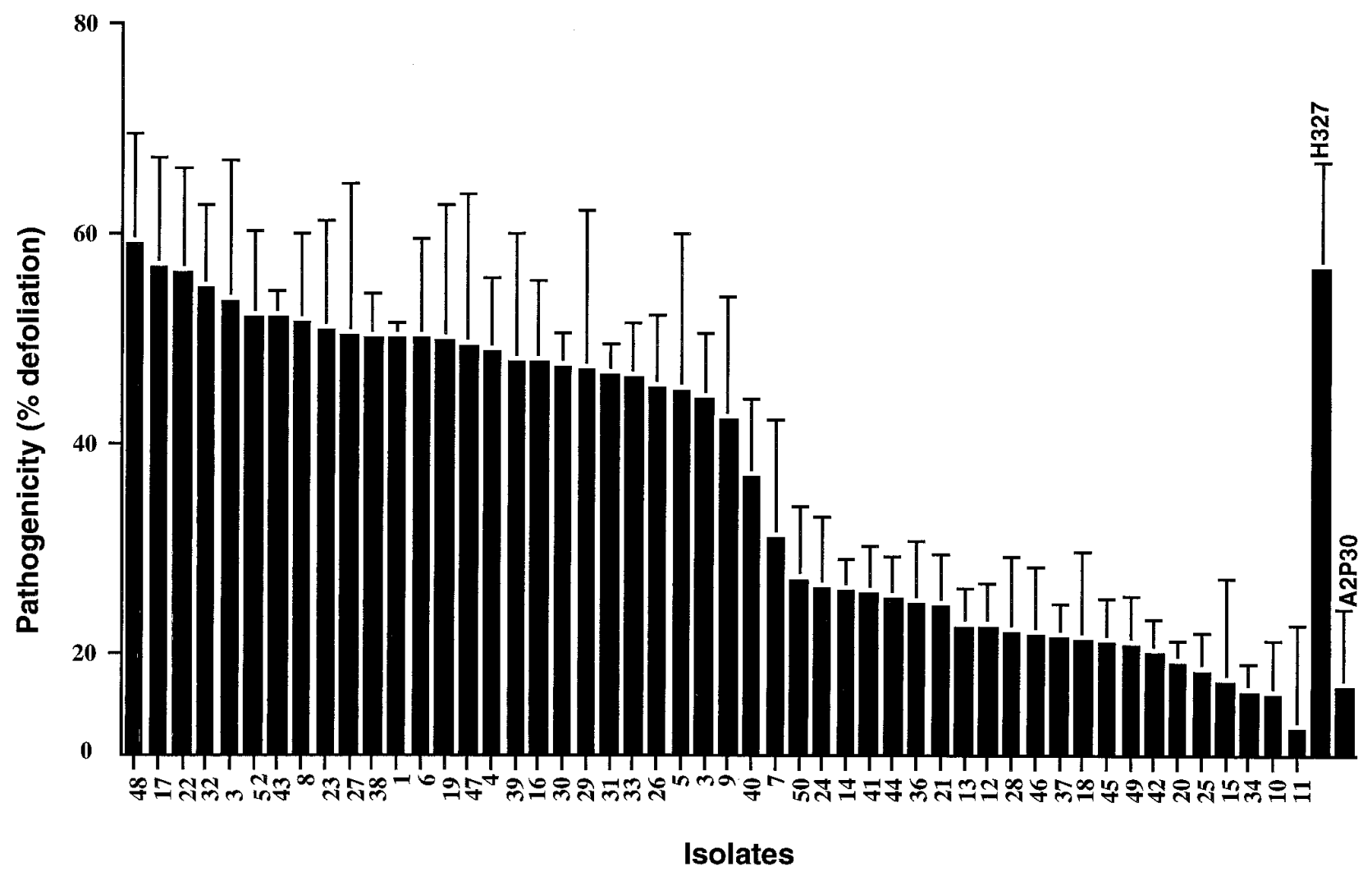

Fig. 2. Pathogenicity distribution for 50 single-ascospore progeny from a backross between a highly aggressive parent (H327) and a moderately aggressive $\mathrm{F}_{1}$ strain (A2P30) of Ophiostoma novo-ulmi. Inoculations were carried out on U. procera in July 1997 and crown defoliation was assessed 10 weeks after inoculation. Vertical bars indicate standard error. Progeny strains were inoculated into four replicate trees, whereas parents were inoculated into eight replicate trees.

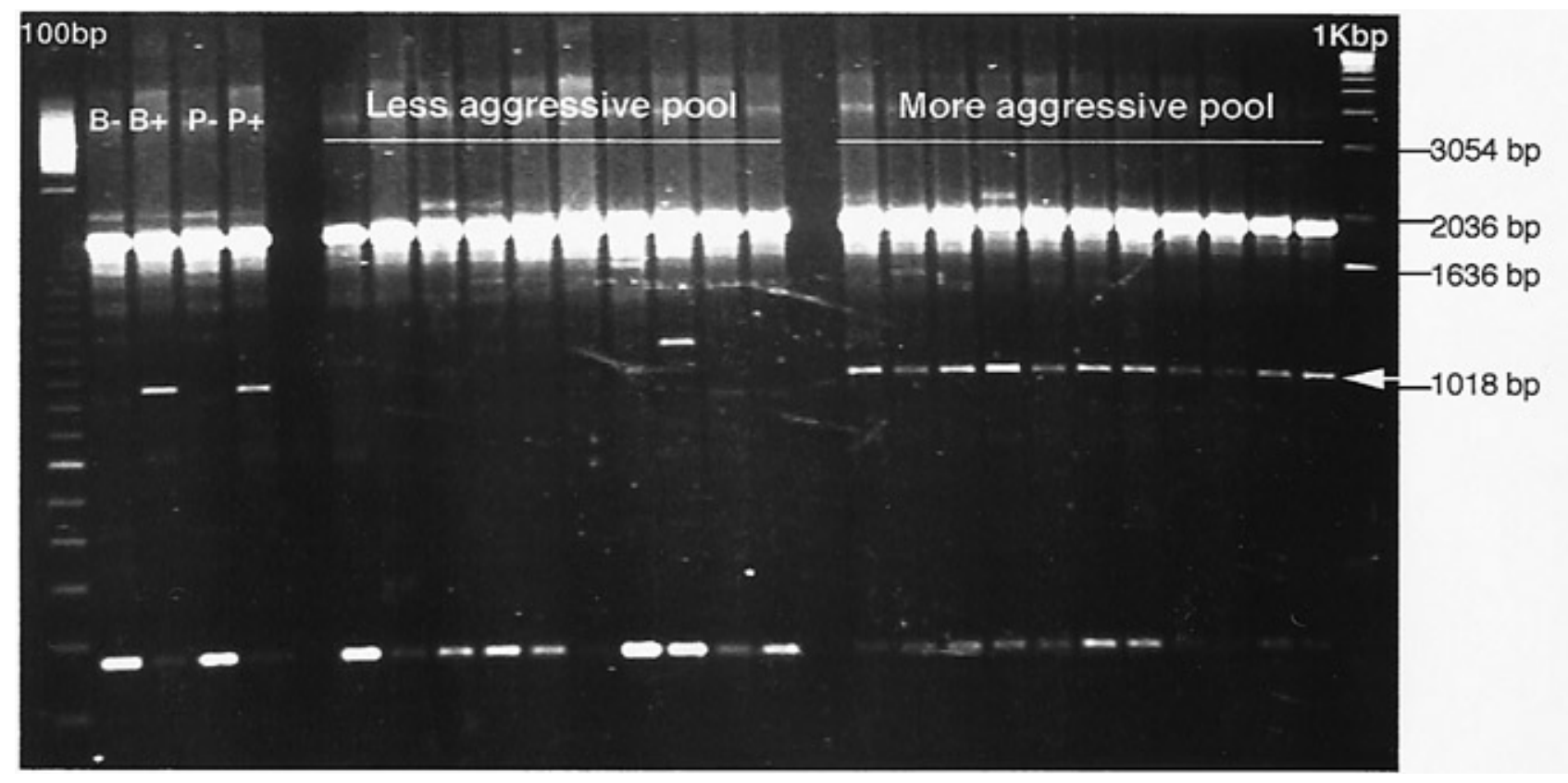

Fig. 3. Cosegregation of random amplified polymorphic DNA (RAPD) marker OPK $3_{1050}$ (arrow) with pathogenicity gene Pat1 of Ophiostoma novoulmi. $\mathrm{B}-$ and $\mathrm{B}+$ : bulked DNA from 12 moderately and 12 highly aggressive $\mathrm{F}_{1}$ progeny, respectively. $\mathrm{P}-$ and $\mathrm{P}+$ : DNA from moderately and highly aggressive parents AST27 and H327, respectively. 
Dist Marker Name

$\mathrm{cM}$

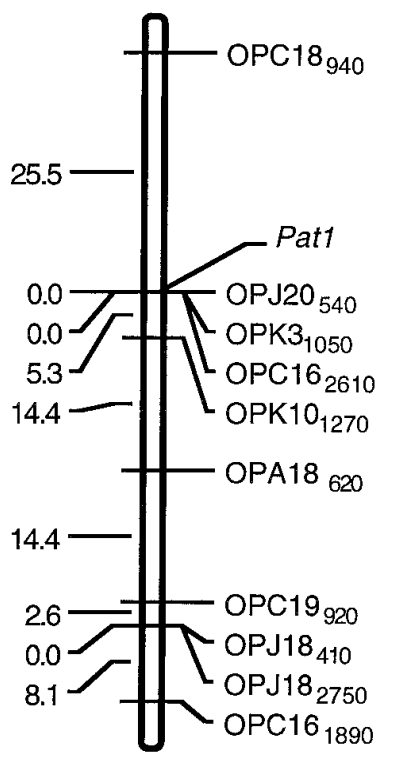

A

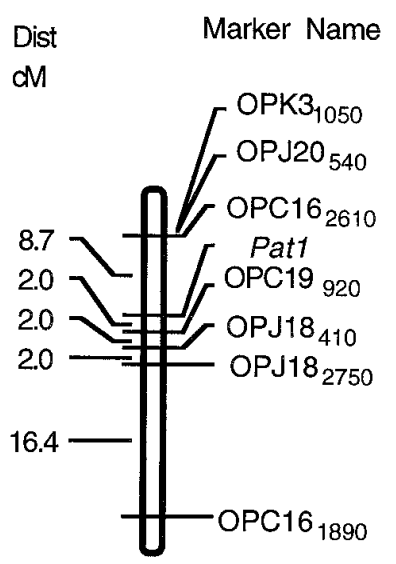

B

Fig. 4. Meiotic mapping of random amplified polymorphic DNA (RAPD) loci linked to pathogenicity gene Patl of Ophiostoma novoulmi. A, Linkage map based on analysis of $40 \mathrm{~F}_{1}$ single-ascospore progeny from the cross H327 (Pat1-h) $\times$ AST27 (Pat1-m). B, Linkage map based on analysis of 50 single-ascospore progeny from the backcross H327 (Pat1-h) × A2P30 (Pat1-m). Map distances were calculated from multipoint analysis (LOD score of 4.0 and Theta of 0.3 ) with the software MAPMAKER version 2.0 for Macintosh (Lander et al. 1987).

with the RAPD probe OPK $3_{1050}$ linked to Pat1 suggested that the chromosome carrying Patl was the one corresponding to chDNA II, with a size estimated at $3.5 \mathrm{Mb}$ (Fig. 6B).

\section{RAPD comparison of $O$. ulmi and $O$. novo-ulmi.}

DNA from strains of $O$. ulmi (Q412T, W9, and R21), EAN O. novo-ulmi (H327, AST27, AST20, and CKT11), and NAN O. novo-ulmi (FG245, W2, MH75, and 16K) was amplified with 80 RAPD primers and the amplicons were separated by gel electrophoresis. The data, based on 153 clear and reproducible amplicons, indicated that 36 markers were common to all $O$. ulmi and $O$. novo-ulmi isolates, whereas 51 markers were present in all the $O$. novo-ulmi isolates but not in any of the $O$. ulmi isolates. Other markers were either specific to $O$. ulmi (40 markers), or to the EAN (13 markers) or NAN (8 markers) races of $O$. novo-ulmi. Five markers were present both in $O$. ulmi and in the moderately aggressive EAN $O$. novo-ulmi strain AST27 (Fig. 7). These included two amplicons $\left(\mathrm{OPC} 16_{1890}\right.$ and $\left.\mathrm{OPJ} 18_{2750}\right)$ linked to the less pathogenic Pat1-m allele (Fig. 4), and three amplicons (OPA12 ${ }_{1880}$, OPC19 1920 , and OPK5 $5_{1060}$ ) that were not linked to the Pat1 locus.

\section{DISCUSSION}

As a result of the steady geographical displacement of $O$. ulmi by O. novo-ulmi since the 1940s (Brasier 1990), the latter has become the main Dutch elm disease agent against which disease controls must be directed. Understanding the genetic control of pathogenicity is basic to developing disease controls involving the genetic manipulation of the pathogen or the host. In this study, we have investigated the hypothesis that an EAN isolate of $O$. novo-ulmi with a level of pathogenicity

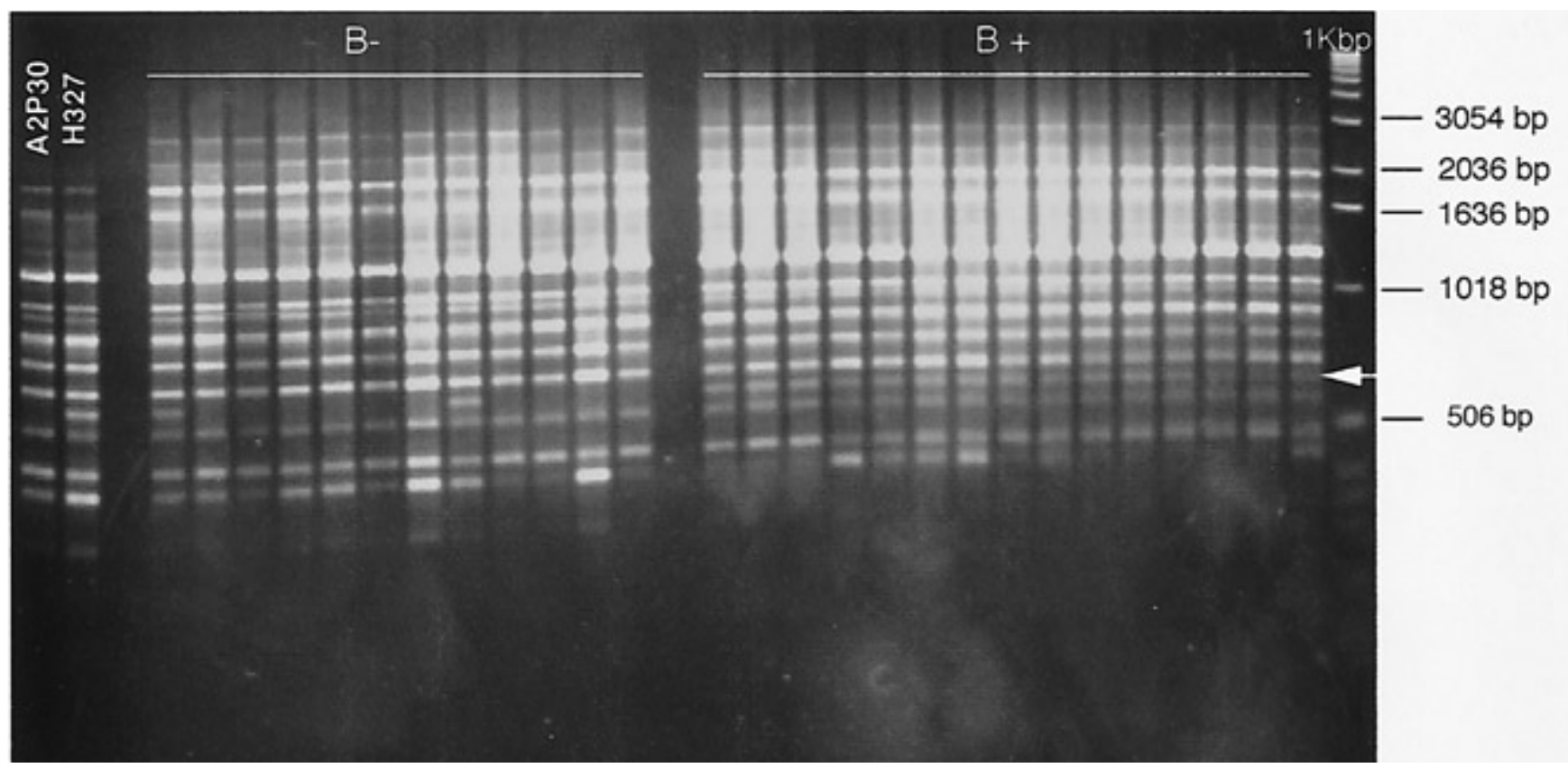

Fig. 5. Cosegregation of random amplified polymorphic DNA (RAPD) marker OPJ $20_{540}$ (arrow) with pathogenicity gene Pat1 in progeny from backross H327 (Pat1-h) × A2P30 (Pat1-m). B2- and B2+: DNA from moderately and highly aggressive backcross progeny, respectively. A2P30 and H327: DNA from moderately and highly aggressive parents, respectively. The marker is present in all 15 B2+ DNA samples shown here, whereas it occurs in only 2 of the 12 B2- samples. 
outside the normal range for the species, AST27, carries a single gene for this effect (Brasier 1987). In field inoculation tests, phenotypes for high and moderate pathogenicity in the cross $\mathrm{H} 327 \times$ AST27 again segregated $1: 1$ in the $F_{1}$ progeny. This confirmed that the effect is most probably controlled by a single gene, termed Pat1, with two alleles Patl-h and Patl-m conferring high and moderate levels of pathogenicity, respectively. The result was further corroborated by a backcross between $\mathrm{H} 327$ and a moderately pathogenic $\mathrm{F}_{1}$ progeny isolate (A2P30) in which the two pathogenicity classes again segregated $1: 1$. To our knowledge, Patl is the first putative pathogenicity gene to be identified in $O$. novo-ulmi. Statistical

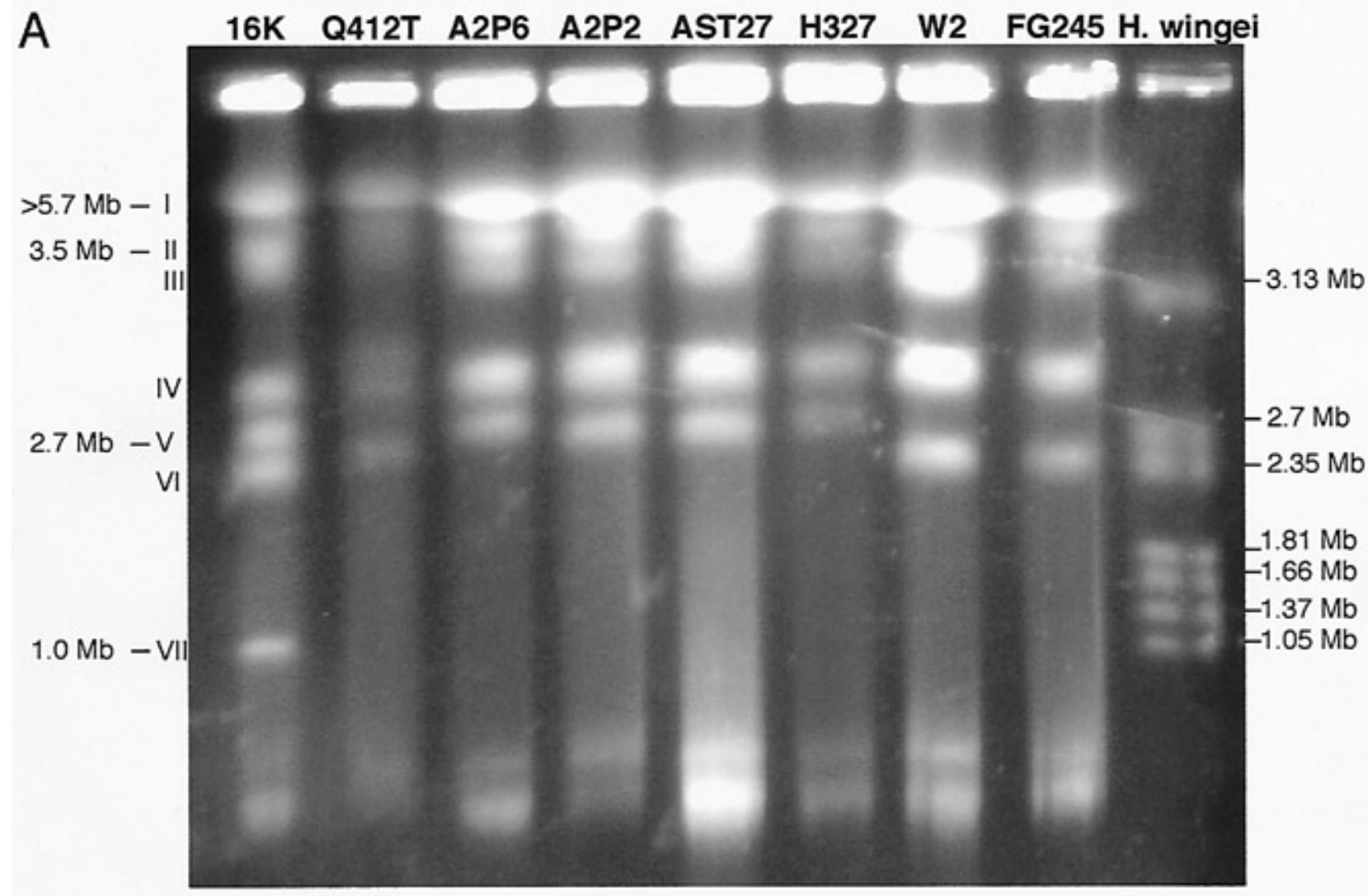

$\mathrm{B}$

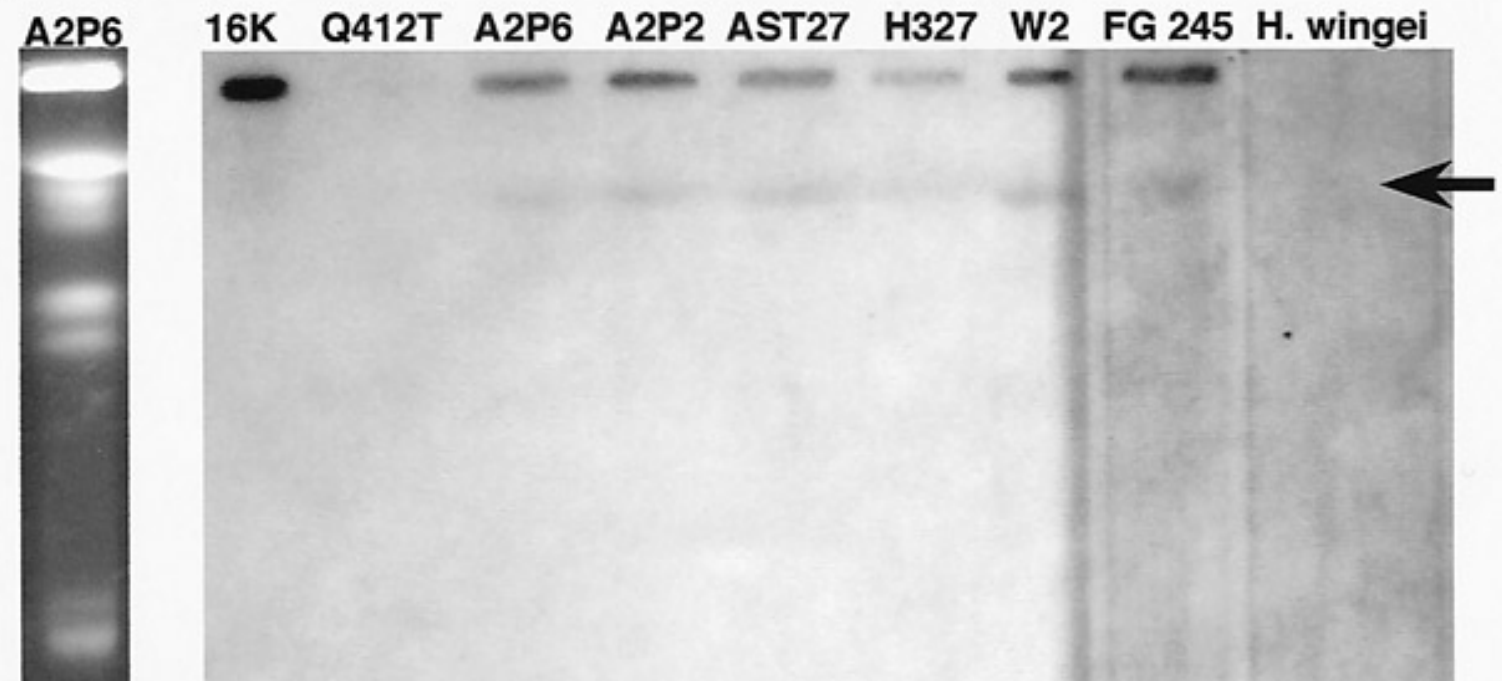

Fig. 6. A, Chromosomal DNA of Ophiostoma ulmi and O. novo-ulmi separated by pulsed-field gel electrophoresis (PFGE; Hansenula wingei; FG245, W2 and 16K: North American [NAN] O. novo-ulmi; H327, AST27, A2P2, and A2P6: Eurasian [EAN] O. novo-ulmi; Q412T: O. ulmi). Electrophoresis conditions used were a 15 to 30 min linearly ramped switching interval at $2 \mathrm{~V} / \mathrm{cm}$ for total run times ranging from 96 to $112 \mathrm{~h}$. The included angle between the electric fields was $106^{\circ}$. B, Southern hybridization (arrow) of chromosomal DNA with radioactive probe prepared from random amplified polymorphic DNA (RAPD) marker OPK $3_{1050}$ linked to Pat1. Signal is present in all O. novo-ulmi isolates but absent in O. ulmi (Q412T) and H. wingei. 
analysis of inoculation data also suggested, in agreement with Brasier (1987), that additional, minor genes are involved in the smaller but significant variation in aggressiveness within each pathogenicity class, but this was not investigated any further.

Unusually low levels of defoliation were obtained on Ulmus $\times$ Commelin following the pathogenicity tests conducted in June 1995, although internal vascular streaking was extensive. Based on an analysis of 15 years of field tests with H327, AST27, and another EAN tester isolate, Sutherland et al. (1997) reported that external symptom expression in elms inoculated with $O$. novo-ulmi is correlated with sunlight intensity and temperature, and that external symptom development and internal colonization by the pathogen are not necessarily coupled. High temperatures and high sunlight conditions, in particular, were shown to be conducive to low levels of defoliation. These conditions prevailed in England in the summer of 1995.

In the backcross $\mathrm{H} 327 \times \mathrm{A} 2 \mathrm{P} 30$, two progeny isolates (A3P7 and A3P40) exhibited phenotypes intermediate between the higher and lower pathogenicity classes. This most probably reflects variability in replicates, i.e., these two progeny might be reclassified into one or another class in a further test. Indeed, the distribution of their replicate values suggests that they belong to the lower and higher pathogenicity classes, respectively. Another possibility is that the lower pathogenicity phenotype of AST27 is due to the presence of alleles at two tightly linked loci that co-segregate at meiosis, and that A3P7 and A3P40 are intermediate recombinants. Additional crosses would be required to test this hypothesis. However, no such "intermediate" phenotypes were obtained in the previous field tests, involving a total of $68 \mathrm{~F}_{1}$ progeny isolates.

Most published uses of BSA (Michelmore et al. 1991) have dealt with identification of markers linked to resistance genes in crops (e.g., Martin et al. 1991; Penner et al. 1993; Barua et al. 1993) but RAPD markers linked to fungal genes have also been identified (e.g., Shi and Leung 1994). BSA and pooling of recombination data have allowed us to quickly locate 10 RAPD markers linked to the Patl locus in O. novo-ulmi. Recombination analysis has also indicated that the mating-type (MAT) locus, which has been proposed to modulate pathogenicity in O. novo-ulmi (Brasier 1988), segregated independently from Pat1 and from the 10 RAPD loci linked to it (A. Et-Touil and L. Bernier, unpublished).

Comparative RAPD analysis of 11 strains representing $O$. $u l m i$ and the EAN and NAN races of $O$. novo-ulmi resulted in

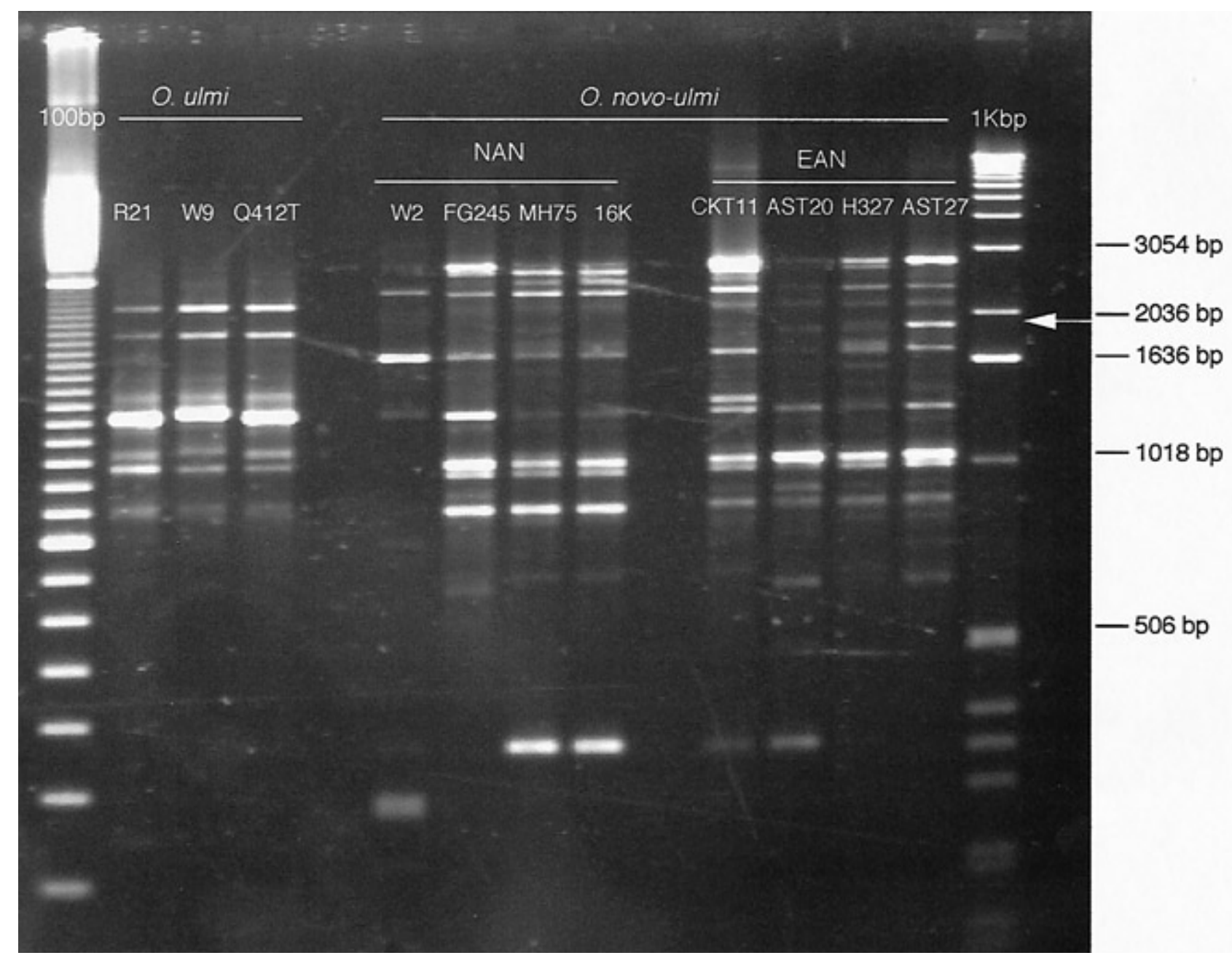

Fig. 7. Comparative DNA amplification patterns of Ophiostoma ulmi and O. novo-ulmi. Marker OPC16 $6_{1890}$ (arrow) is present in Eurasian [EAN] strain AST27 and in the O. ulmi strains Q412T, W9, and R21. 
levels of discrimination of these taxa similar to that reported previously by Bates et al. (1993) and Pipe et al. (1995) on the basis of restriction fragment length polymorphism (RFLP) and RAPD data. In addition, we observed that five of the amplicons found in $O$. ulmi were also present in the unusual EAN strain AST27 but not in the other O. novo-ulmi strains tested. Bates et al. (1993) also reported the occurrence of an RFLP marker in AST27 that was typically found in O. ulmi. More recently, Brasier et al. (1998) have demonstrated with both phenotypic and molecular characters that rare interspecific hybrids can arise when $O$. novo-ulmi spreads into an area previously occupied by $O$. ulmi. The hybrids, though unfit, may survive transiently in the saprotrophic phase of the pathogens. It is therefore likely that AST27 is an introgressant or backcross product resulting from an $O$. ulmi $\times$ O. novo-ulmi hybridization event.

Furthermore, BSA and recombination analysis showed that two of the five $O$. ulmi-specific amplicons present in AST27, OPC $16_{1890}$ and OPJ $18_{2750}$, were linked to the putative moderate pathogenicity allele Pat $1-m$. This suggests that the Pat $1-m$ allele itself may originate not from $O$. novo-ulmi but from the much less aggressive $O$. ulmi. This observation could therefore explain why AST27 falls well below the normal range of aggressiveness found in EAN O. novo-ulmi (Brasier 1986). The presence in the AST27 nuclear genome of three additional O. ulmi-specific amplicons unlinked to the Patl locus indicates that this strain harbors other $O$. ulmi DNA sequences, some of which might also include coding regions. If so, the latter do not appear to have a comparably marked effect on pathogenicity, since the high and moderate pathogenicity phenotypes segregated $1: 1$ in the $\mathrm{H} 327 \times$ AST27 cross.

PFGE revealed variation in both chDNA size and number among the strains analyzed, though a small (1 Mb) chDNA found in NAN O. novo-ulmi strain 16K (Dewar and Bernier 1993, 1995; Dewar et al. 1997) was not observed among the other strains analyzed in this study. Chromosome polymorphisms among strains $\mathrm{H} 327$, AST27, and two $\mathrm{F}_{1}$ progeny (A2P2 and A2P6) did not correlate with pathogenicity, since strains AST27 (Pat-m) and A2P2 (Pat-h) had similar karyotypes. A Southern hybridization of PFGE-separated chromosomes with RAPD probe OPK $3_{1050}$, linked to Pat1, indicated that the chromosome carrying Patl was the one of approximately $3.5 \mathrm{Mb}$ corresponding to chDNA II (Fig. 6). If this physical localization of Patl is confirmed and chDNA II can be further separated from neighboring chDNA bands, it may be possible to clone the gene from a chromosome-specific library and elucidate its product and its role in pathogenesis. Pat1 could code for a molecule directly involved in pathogenesis or act as a regulatory element of other genes involved in the host-pathogen interaction. Cloning of Patl should also confirm whether or not it is introgressed from O. ulmi.

\section{MATERIALS AND METHODS}

\section{Media and isolates.}

Malt extract agar (MEA), elm sapwood agar (ESA), and Tchernoff's liquid medium were prepared according to Brasier (1981), whereas ESA supplemented with linoleic acid (ESALA) was prepared as described by Bernier and Hubbes (1990). Moderately pathogenic EAN O. novo-ulmi strain
AST27 was isolated from Assalem Forest, Elburz Mountains, Iran, in 1977 by C. M. Brasier, and highly pathogenic strain H327 from Bratislava, Czechoslovakia, in 1979 by H. Jamnicky. These two isolates have been used extensively for over 15 years as controls in field pathogenicity trials (e.g., Sutherland et al. 1997; Brasier et al. 1998).

For long-term storage, $\mathrm{F}_{1}$ and backcross progeny strains and their parents were grown individually in shake culture in liquid complete medium (Bernier and Hubbes 1990). The resulting yeastlike cells were mixed with glycerol to a final concentration of $15 \%$ and stored at $-80^{\circ} \mathrm{C}$ (Bernier 1993).

\section{Controlled crosses and elm inoculations.}

Highly aggressive isolate H327 (MAT A) and moderately aggressive isolate AST27 (MAT B) were crossed in the laboratory on ESA medium by the patch fertilization method (Brasier 1981). Single ascospores were isolated onto MEA medium as described by Webber et al. (1986) and Bernier and Hubbes (1990). Forty of the resulting $F_{1}$ progeny were selected at random and evaluated together with their parents under field conditions over 2 consecutive years at the UK Forestry Commission's Headley Research Nursery (see Sutherland et al. 1997). Inoculum was prepared in Tchernoff's liquid culture medium as previously described (Brasier 1981).

The first pathogenicity trial was carried out on 5-year-old clonal Ulmus $\times$ Commelin (Brasier 1986) on 22 June 1995. Each progeny isolate was inoculated into three replicate trees and the parents into 10 trees. Two drops of a spore suspension of $1 \times 10^{6}$ spores per $\mathrm{ml}$ were introduced into a wound on the main stem made with a sterile scalpel blade halfway up the crown. A second pathogenicity trial was carried out on 5-yearold clonal U. procera on 17 June 1996. There were four replicate trees per progeny isolate and eight replicates per parent. Inoculum was introduced one fifth of the way down the crown.

Twelve weeks after inoculation, the percentage of defoliation for each tree was scored by three independent assessors and the overall defoliation per isolate calculated. In 1995, destructive sampling was also carried out on all trees inoculated with the parents and on the replicate trees of 14 progeny isolates. The extent of internal vascular streaking was then calculated as a percentage, by dividing the distance between the lowest branch showing streaking and the top of the crown (d) by the overall height of the crown (h), i.e., $d / h \%$.

In 1997, a moderately aggressive $\mathrm{F}_{1}$ progeny isolate, A2P30 (MAT B), was backcrossed to the highly aggressive parent H327 on ESALA medium and single-ascospore colonies obtained as above. Fifty progeny from this cross were inoculated into 5-year-old clonal U. procera on 1 July 1997 with four replicate trees per progeny and eight replicates per parent. Percentage of defoliation was assessed as above but after 10 weeks.

\section{DNA extraction and amplification.}

Mycelium for DNA extraction was grown in 125-ml Erlenmeyer flasks containing $50 \mathrm{ml}$ of liquid complete medium. The flasks were seeded with four mycelium plugs, placed on an AR2P6040 rotary shaker at $110 \mathrm{rpm}$ (Électronique MA, Québec, Québec, Canada) and incubated at $22^{\circ} \mathrm{C}$ for 7 days. The cultures were then centrifuged at $4,700 \times \mathrm{g}$ for $10 \mathrm{~min}$; the supernatant was removed; and the pellets were washed 
with sterile, distilled water, lyophilized, and ground in liquid nitrogen. Total genomic DNA was extracted according to Zolan and Pukkila (1986). DNA concentrations were estimated from agarose gel electrophoresis, by comparison with known quantities of undigested lambda DNA.

DNA was amplified by PCR with RAPD primers (Operon Technologies, Alameda, CA). BSA (Michelmore et al. 1991) was used to find markers linked to the putative pathogenicity gene in O. novo-ulmi. Bulked DNAs were prepared from 12 highly aggressive and 12 moderately aggressive $F_{1}$ progeny. The bulked DNA and parent DNA were then screened for differences with 80 RAPD primers (Operon kits A, C, J, and K).

The PCR template consisted of $0.5 \mathrm{ng}$ of fungal DNA from either an individual or a bulk sample. The reactions were performed in a total volume of $12.5 \mu \mathrm{l}$ containing $10 \mathrm{mM}$ Tris$\mathrm{HCl}, \mathrm{pH} 8.3,50 \mathrm{mM} \mathrm{KCl}, 2 \mathrm{mM} \mathrm{MgCl} 2,100 \mu \mathrm{M}$ concentrations of dNTP (Pharmacia, Baie d'Urfé, Québec, Canada), and Taq DNA polymerase (Boehringer Mannheim, Laval, Québec, Canada) at a final concentration of $0.04 \mathrm{U} / \mu \mathrm{l}$. Forty-five cycles of PCR were done on a 9600 thermal cycler (PerkinElmer, Norwalk, CT): 20 cycles of $1 \mathrm{~min}$ at $94^{\circ} \mathrm{C}$ (denaturation), $1 \mathrm{~min}$ at $37^{\circ} \mathrm{C}$ (annealing) and $1 \mathrm{~min}$ at $72^{\circ} \mathrm{C}$ (elongation); 25 cycles of $1 \mathrm{~min}$ at $94^{\circ} \mathrm{C}, 1 \mathrm{~min}$ at $37^{\circ} \mathrm{C}$ and 1 min at $72^{\circ} \mathrm{C}$ followed by $5 \mathrm{~s}$ of auto-extension per cycle; 10 $\min$ at $72^{\circ} \mathrm{C}$. PCR amplification products were electrophoresed in $1 \%$ agarose and $0.5 \%$ synergel (Diversified Biotechnologies, Boston) gels in $0.09 \mathrm{M}$ Tris-phosphate and 0.002 M EDTA. Nucleic acids were visualized by ethidium bromide fluorescence.

\section{Chromosomal DNA preparations and PFGE.}

Chromosomal DNA (chDNA) was isolated from spheroplasts of 5- to 7-day-old budding cell suspensions of $O$. ulmi (Q412T) and $O$. novo-ulmi (NAN race control isolates: FG245, W2, and 16K; EAN race: H327, AST27, and progeny A2P2 $\left[\mathrm{F}_{1}+\right]$ and A2P6 $\left[\mathrm{F}_{1}-\right]$ ), (Dewar and Bernier 1993). chDNA plugs, stored in $0.5 \mathrm{M}$ EDTA (pH 8)-1\% Sarkosyl at $4{ }^{\circ} \mathrm{C}$, were washed extensively in electrophoresis buffer prior to each PFGE experiment. chDNAs were analyzed with a CHEF-DRIII (Bio-Rad, Mississauga, Ontario, Canada) system. Gels, composed of $1 \%$ Seakem GTG agarose (FMC BioProducts, Guelph, Ontario, Canada) were electrophoresed in $0.5 \times$ TBE (45 mM Tris-borate, $1 \mathrm{mM}$ EDTA) at $14^{\circ} \mathrm{C}$. The electrophoresis conditions used were a 15 to 30 min linearly ramped switching interval at $2 \mathrm{~V} / \mathrm{cm}$ for total run times ranging from 96 to $112 \mathrm{~h}$ (Dewar and Bernier 1993). The included angle between the electric fields was $106^{\circ}$. The chDNAs from the Saccharomyces cerevisiae strain YNN295 (FMC BioProducts), the Schizosaccharomyces pombe strain 972 (FMC BioProducts), and the Hansenula wingei strain Y-B-4662-VIA (Bio-Rad) were used as chromosomal size standards.

\section{Southern transfers, DNA probes,} and hybridization conditions.

chDNA was transferred from pulsed-field gels to charged nylon membranes by capillarity overnight in $4 \times$ SSC $(1 \times$ SSC is $0.15 \mathrm{M} \mathrm{NaCl}$ plus $0.015 \mathrm{M}$ sodium citrate) with a 15 -min pre-treatment in $0.24 \mathrm{~N} \mathrm{HCl}, 0.4 \mathrm{M} \mathrm{NaOH}-0.6 \mathrm{M} \mathrm{NaCl}$, and $0.5 \mathrm{M}$ Tris-1.5 M NaCl. A DNA probe, prepared from RAPD marker OPK $3_{1050}$ linked to the pathogenicity gene, was purified with an agarose gel DNA extraction kit (Boehringer
Mannheim) and labeled with ${ }^{32} \mathrm{P}$-dCTP with T7 Quik Prime (Pharmacia). The labeled probe was purified on a Sephadex G-50 spin column and used at a concentration of 1 to $4 \times 10^{5}$ $\mathrm{dpm} / \mathrm{ml}$ for hybridization overnight at $65^{\circ} \mathrm{C}$ in Church buffer. After hybridization, the membrane was washed twice for 15 min at $65^{\circ} \mathrm{C}$ in $100 \mathrm{ml}$ of $1 \times \mathrm{SSC}-1 \%$ sodium dodecyl sulfate (SDS) before being exposed to autoradiographic films at $-80^{\circ} \mathrm{C}$ (Church and Gilbert 1984).

\section{Linkage analysis.}

Recombination among the 10 RAPD markers identified by BSA was studied in all 40 progeny from cross H327 × AST27, with MAPMAKER for the Macintosh version 2.0 software (Lander et al. 1987) provided by S. V. Tingey (Du Pont, Wilmington, DE). The segregation of each marker fragment was studied by scoring the presence or absence of a band in the progeny. Linkage between RAPD markers and the putative pathogenicity gene was verified with a LOD score of 4.0 and Theta value of 0.3. Markers were first mapped by two-point analysis, and then by multipoint analysis. The same procedure was used for linkage analysis of a second set of 50 progeny from the backcross $\mathrm{H} 327 \times \mathrm{A} 2 \mathrm{P} 30$.

\section{Statistical analysis of pathogenicity.}

All statistical analyses were performed with the SAS version 6.1 software package (SAS Institute, Carey, NC). Pathogenicity values for progeny from crosses $\mathrm{H} 327 \times$ AST27 and $\mathrm{H} 327 \times \mathrm{A} 2 \mathrm{P} 30$ were first subjected to analysis of variance (ANOVA) followed by Duncan's multiple comparison test to verify the occurrence of phenotypically different classes within the progeny. A chi-square test was used to verify if different classes segregated in a 1:1 ratio.

\section{ACKNOWLEDGMENTS}

This work was supported by grants from the Natural Sciences and Engineering Research Council of Canada (NSERC) and Fonds FCAR (Québec) to L. B. We wish to thank Josée Dufour (Université Laval) and Susan Kirk (Forest Research, UK) for technical assistance and S. V. Tingey for providing the Macintosh version of MAPMAKER.

\section{LITERATURE CITED}

Barua, U. M., Chalmers, K. J., Hackett, C. A., Thomas, W. T. B., Powell, W., and Waugh, R. 1993. Identification of RAPD markers linked to a Rhynchosporium secalis resistance locus in barley using near-isogenic lines and bulk segregant analysis. Heredity 71:177-184.

Bates, M. R., Buck, K. W., and Brasier, C. M. 1993. Molecular relationship between Ophiostoma ulmi and the NAN and EAN races of $O$. novo ulmi determined by restriction fragment length polymorphism of nuclear DNA. Mycol. Res. 97:449-455.

Bernier, L. 1983. Relationships between isoenzymes, cultural characters, and pathogenicity in Ceratocystis ulmi (Buism.) C. Moreau. M.Sc.F. thesis. University of Toronto, Toronto.

Bernier, L. 1993. Conventional and molecular genetic approaches to the study of pathogenicity in Ophiostoma ulmi sensu lato. Pages 293-321 in: Dutch Elm Disease Research: Cellular and Molecular Approaches. M. B. Sticklen and J. L. Sherald, eds. Springer-Verlag, New York.

Bernier, L., and Hubbes, M. 1990. Mutations in Ophiostoma ulmi induced by $N$-methyl- $N$-nitro- $N$-nitrosoguanidine. Can. J. Bot. 68:225231

Bowden, C. G., Smalley, E., Guries, R. P., Hubbes, M., Temple, B., and Horgen, P. A. 1996. Lack of association between cerato-ulmin production and virulence in Ophiostoma novo-ulmi. Mol. Plant-Microbe Interact. 9:556-564.

Brasier, C. M. 1977. Inheritance of pathogenicity and cultural characters 
in C. ulmi. Hybridization of protoperithecial and non-aggressive strains. Trans. Br. Mycol. Soc. 68:45-52.

Brasier, C. M. 1979. Dual origin of recent Dutch elm disease outbreaks in Europe. Nature 281:78-79.

Brasier, C. M. 1981. Laboratory investigation of Ceratocystis ulmi. Pages 76-79 in: Compendium of Elm Diseases. R. J. Stipes and R. J. Campana, eds. American Phytopathological Society St. Paul, MN.

Brasier, C. M. 1986. A comparison of pathogenicity and cultural characteristics in the EAN and NAN aggressive sub-groups of Ophiostoma ulmi. Trans. Br. Mycol. Soc. 87:1-13.

Brasier, C. M. 1987. Some genetical aspects of necrotrophy with special reference to Ophiostoma ulmi. Pages 297-310 in: Genetics and Plant Pathogenesis. P. R. Day and G. J. Jellis, eds. Blackwell Scientific Publications, Oxford.

Brasier, C. M. 1988. Ophiostoma ulmi, cause of Dutch elm disease. Pages 207-223 in: Advances in Plant Pathology. Vol. 5. G. S. Sidhu, ed. Academic Press, New York.

Brasier, C. M. 1990. China and the origins of Dutch elm disease: An appraisal. Plant Pathol. 39:5-16.

Brasier, C. M. 1991. Ophiostoma novo-ulmi sp. nov., causative agent of the current Dutch elm disease pandemics. Mycopathologia 115:151161.

Brasier, C. M., Kirk, S. A., Pipe, N., and Buck, K. W. 1998. Rare interspecific hybrids in natural populations of the Dutch elm disease pathogens Ophiostoma ulmi and O. novo-ulmi. Mycol. Res. 102:4557.

Brasier, C. M., Kirk, S. A., and Tegli, S. 1995. Naturally occurring non cerato-ulmin producing mutants of Ophiostoma novo-ulmi are pathogenic but lack aerial mycelium. Mycol. Res. 99:436-440.

Brasier, C. M., and Mehrotra, M. D. 1995. Ophiostoma himal-ulmi sp. nov., a new species of Dutch elm disease fungus endemic to the Himalayas. Mycol. Res. 99:205-215

Brasier, C. M., Takai, S., Nordin, J. H., and Richards, W. C. 1990. Differences in cerato-ulmin production between the EAN, NAN and nonaggressive subgroups of Ophiostoma ulmi. Plant Pathol. 39:231-236.

Church, G. M., and Gilbert, W. 1984. Genomic sequencing. Proc. Natl. Acad. Sci. USA 81:1991-1995.

Dewar, K., and Bernier, L. 1993. Electrophoretic karyotypes of the elm tree pathogen Ophiostoma ulmi (sensu lato). Mol. Gen. Genet. 238: 381-383.

Dewar, K., and Bernier, L. 1995. Inheritance of chromosome-length polymorphisms in Ophiostoma ulmi (sensu lato). Curr. Genet. 27:541549.

Dewar, K., Bousquet, J., Dufour, J., and Bernier, L. 1997. A meiotically reproducible chromosome length polymorphism in the ascomycete fungus Ophiostoma ulmi (Sensu lato). Mol. Gen. Genet. 225:38-44.

Kile, G. A., and Brasier, C. M. 1990. Inheritance and inter-relationship of fitness characters in progeny of an aggressive $\times$ non-aggressive cross of Ophiostoma ulmi. Mycol. Res. 94:514-522.

Lander, E. S., Green, P, Abrahamson, J., Barlow, A., Daly, M. J., Lincoln, S. E., and Newburg, L. 1987. MAPMAKER: An interactive computer package for constructing primary genetic linkage maps of experimental and natural populations. Genomics 1:174-181.

Martin, G. B., Williams, J. G. K., and Tanksley, S. D. 1991. Rapid identification of markers linked to a Pseudomonas resistance gene in tomato by using random primers and near-isogenic lines. Proc. Natl. Acad. Sci. USA 88:2336-2340.

Michelmore, R. W., Paran, I., and Kessell, R. V. 1991. Identification of markers linked to disease resistance genes by bulked segregant analysis: A rapid method to detect markers in specific genomic regions using segregating populations. Proc. Natl. Acad. Sci. USA 88:9828-9832.

Penner, G. A., Chong, J., Levesque-Lemay, M., Molnar, S. J., and Fedak, G. 1993. Identification of a RAPD marker linked to the oat stem rust gene $p g 3$. Theor. Appl. Genet. 85:702-705.

Pipe, N. D., Buck, K. W., and Brasier, C. M. 1995. Molecular relationships between Ophiostoma ulmi and the NAN and EAN races of $O$. novo-ulmi determined by RAPD markers. Mycol. Res. 99:653-658.

Scheffer, R. J., Liem, J. I., and Elgersma, D. M. 1987. Production in vitro of phytotoxic compounds by non-aggressive and aggressive isolates of Ophiostoma ulmi, the Dutch elm disease pathogen. Physiol. Mol. Plant Pathol. 30:321-335.

Shi, Z., and Leung, H. 1994. Genetic analysis and rapid mapping of a sporulation mutation in Magnaporthe grisea. Mol. Plant-Microbe Interact. 7:113-120

Sutherland, M. L., Pearson, S., and Brasier, C. M. 1997. The influence of temperature and light on defoliation levels of elm by Dutch elm disease. Phytopathology 87:576-581.

Takai, S. 1980. Relationship of the production of the toxin, ceratoulmin, to synnemata formation, pathogenicity, mycelial habit, and growth of Ceratocystis ulmi isolates. Can. J. Bot. 58:658-662.

Temple, B., Horgen, P. A., Bernier, L., and Hintz, W. E. 1997. Ceratoulmin, a hydrophobin secreted by the causal agents of Dutch elm disease, is a parasitic fitness factor. Fungal Genet. Biol. 22:39-53.

Webber, J. F., Mitchell, A. G., and Smith, F. 1986. Linkage of the genes determining mating type and fungicide tolerance in Ophiostoma ulmi. Plant Pathol. 35:512-516.

Zolan, M., and Pukkila, P. 1986. Inheritance of DNA methylation in Coprinus cinereus. Mol. Cell. Biol. 6:195-200. 